\title{
The role of phosphoinositide 3-kinase in spreading osteoclasts induced by colony-stimulating factor-1
}

\author{
S Palacio and R Felix \\ Department Clinical Research, Bone Biology, University of Bern, Bern, Switzerland \\ (Correspondence should be addressed to R Felix, Department Clinical Research, Bone Biology, University of Bern, Murtenstrasse 35, CH-3010 Bern, \\ Switzerland; Email: felix@dkf5.unibe.ch)
}

\begin{abstract}
Background: Colony-stimulating factor-1 (CSF-1), a growth and survival factor for osteoclasts, stimulates these cells to spread and migrate towards a gradient of CSF-1. This may support the translocation of osteoclasts to new sites on the bone surface to be resorbed. Phosphoinositide 3-kinase (PI 3-K) is a lipid kinase participating in various signal transduction pathways.

Objective: To investigate the role of PI 3-K in the CSF-1-induced spreading of osteoclasts.

Methods: In isolated rat osteoclasts treated with or without CSF-1, the distribution of PI 3-K and proteins phosphorylated on tyrosine were investigated using immunofluorescence. In murine osteoclast-like cells grown from bone marrow cells co-cultured with osteoblasts, the activation of the PI 3-K by CSF-1 was determined both in vivo and in vitro. In vivo, the enzyme product in the cell was determined after extraction and separation with thin layer chromatography; in vitro, PI 3-K activity was measured in the pellet immunoprecipitated from the cell lysate.

Results: Inhibition of PI 3-K blocked the CSF-1-induced spreading of osteoclasts. In spreading osteoclasts, a portion of PI 3-K was translocated to the periphery where proteins phosphorylated on tyrosine appeared simultaneously. In osteoclast-like cells, CSF-1 stimulated PI 3-K activity. This activity could be immunoprecipitated with antibody against phophotyrosine residues.

Conclusion: PI 3-K participates in the CSF-1-induced spreading of osteoclasts. The activated PI 3-K may induce the reorganization of the cytoskeleton resulting in spreading and migration.
\end{abstract}

European Journal of Endocrinology 144 431-440

\section{Introduction}

Colony-stimulating factor-1 (CSF-1), also known as macrophage colony-stimulating factor, is one of the hemopoietic growth factors required for proliferation, differentiation, activation and survival of the cells of the mononuclear phagocytic system (1). Its cellular effects are mediated via a high affinity cell surface receptor that belongs to the tyrosine kinase receptor family and is encoded by the proto-oncogene $c-f m s$ (1).

CSF-1 is essential in supporting the development of osteoclasts and, consequently, bone resorption (2). The osteopetrotic mouse strain of the type op proved to be a useful tool to study the function of CSF-1 in this process. Homozygous op/op mice are deficient in the synthesis of biologically active cytokines (3). The op phenotype is characterized by a low number of macrophages and osteoclasts (4), the latter causing the impaired bone resorption that leads to osteopetrosis. Daily injection of CSF-1 into op/op mice induced the formation of osteoclasts and reversed the osteopetrotic phenotype, providing conclusive evidence that the development of osteoclasts depends on this cytokine (5).
Osteoclast precursor cells and mature osteoclasts contain transcripts encoding $c$-fms and express binding sites for CSF-1 (6-8), suggesting that the cytokine not only supports osteoclastogenesis by a direct action on cells of the osteoclast lineage but that it also acts on mature osteoclasts. Indeed, CSF-1 was shown to be necessary for the survival of osteoclasts in vitro. Furthermore, it stimulates spreading and migration against a gradient of CSF-1 (9) and fusion of osteoclasts (10). The effect of CSF-1 on bone resorption is not clear. Experiments with osteoclasts incubated on bone slices demonstrate contradictory results. One group reported inhibition (9), another stimulation (11). Inhibition could be explained by the osteoclast not resorbing bone during migration. By contrast, the osteoclast has to move over the bone surface to initiate new sites of bone resorption; therefore, migration may promote bone resorption. The effects of CSF-1 on bone resorption in vitro might depend on the experimental conditions.

It has been shown that phosphoinositide 3-kinase (PI $3-\mathrm{K})$ is involved in membrane ruffling and chemotaxis induced by platelet-derived growth factor (12). Therefore, we investigated the role of PI 3-K in the spreading 
of osteoclasts induced by CSF-1. Several isoenzymes belong to the PI 3-K family (13). They are lipid kinases that phosphorylate phosphatidylinositols (PtdIns) and its phosphate esters at the D-3 position of the inositol ring. The products of PI 3-Ks act as second messengers in signal transduction, inducing various cellular processes including mitogenesis, transformation, membrane ruffling, regulation of the actin cytoskeleton and vesicle movement $(12,14-16)$.

The most extensively investigated isoform of PI 3-K is a heterodimer consisting of the regulatory subunit $\mathrm{p} 85$ and the catalytic subunit $\mathrm{p} 110$. In vivo, the preferred substrate of this heterodimer is PtdIns-4,5-diphosphate (PtdIns-4,5- $\mathrm{P}_{2}$ ) (13). The regulatory subunit p85 contains two SH2 domains by which it binds to phosphorylated tyrosine residues. This interaction modulates the regulatory subunit and, as a consequence, leads to an activation of the catalytic subunit $(17,18)$. Thus, the heterodimer $\mathrm{p} 85 / \mathrm{p} 110$ is indirectly activated by receptor and non-receptor tyrosine kinases phosphorylating tyrosine residues. Furthermore, the small GTP-binding protein Ras has been found to interact directly with the catalytic subunit of PI 3-K in a GTP-dependent manner through the Ras effector site and to stimulate the enzyme activity (19).

Inhibitors of PI 3-K block bone resorption in vitro and in vivo (20-22). The mechanism by which PI 3-K participates in this process is not fully clear, but some functions have been demonstrated. The enzyme is involved in the formation of ruffled borders (23). When osteoclasts attach to mineralized bone surfaces, they are activated and undergo drastic morphological and functional changes. The cells polarize and form specialized membrane areas along with the reorganization of cytoskeletal structures (24). During this cellular attachment, PI 3-K translocates from the cytosol to the cytoskeleton (25). Inhibition of PI 3-K inhibits the attachment of osteoclasts, suggesting that the enzyme is required for this process.

In the present study, the effect of CSF-1 on PI 3-K of osteoclasts has been investigated. As mentioned above, CSF-1 stimulates the spreading and migration of isolated osteoclasts in vitro (9). We demonstrate that wortmannin, an inhibitor of PI 3-K (26), impairs the CSF-1-induced spreading of osteoclasts, suggesting a role of PI $3-\mathrm{K}$ in this cellular process. Treatment of osteoclasts with CSF-1 leads to a translocation of a portion of the enzyme to the periphery of the cells, where it is localized with proteins phosphorylated on tyrosine. Furthermore, treatment of osteoclast-like cells with CSF-1 results in an activation of PI 3-K.

\section{Materials and methods}

\section{Materials}

Media were obtained from Gibco BRL, Life Technologies, Basel, Switzerland; leupeptin, aprotinin and pepstatin were purchased from Bachem, Bubendorf, Switzerland; phenylmethylsulfonyl-fluoride (PMSF), dithioerythritol (DTT), phosphatidylinositol, phosphatidylserine, phosphatidylinositol-4-phosphate, phosphatidylinositol-4,5-bisphosphate and phosphoinositides purified from brain extract were obtained from Sigma, Buchs, Switzerland and $\left[{ }^{32} \mathrm{P}_{3} \mathrm{H}_{3} \mathrm{PO}_{4}\right.$ (carrierfree, concentration $10 \mathrm{mCi} / \mathrm{ml}$ ) and $\left[\gamma^{-}{ }^{32} \mathrm{P}\right]$ ATP (specific activity $3000 \mathrm{Ci} / \mathrm{mmol}$, concentration $10 \mathrm{mCi} / \mathrm{ml}$ ) was purchased from Amersham Pharmacia Biotech, Bucks, UK). Inorganic salts and organic compounds with small molecular weight were obtained from Merck, Grogg AG, Bern, CH and Fluka AG, Buchs, Switzerland. Recombinant human CSF-1 was generously donated by Cetus Oncology, Chiron Corporation, Emeryville, CA, USA, 1,25-dihydroxycholecalciferol from Hoffmann-LaRoche, Basel, Switzerland and wortmannin was a generous gift from $\mathrm{T}$ Payne, Novartis Pharma AG, Basel, Switzerland.

\section{Cell culture}

In vitro formation of mouse osteoclast-like cells Osteoclast-like cells were grown in $8-\mathrm{cm}$ diameter tissue culture dishes (27) and plated directly onto the plastic of the culture dish instead of onto a collagen gel. Thus, $4.5 \times 10^{6}$ bone marrow cells from femurs and tibias of 6-8-week-old male ddy mice were co-cultured with $1.2 \times 10^{6}$ osteoblasts in $\alpha$-MEM containing Earle's salts, $10 \%$ fetal bovine serum (FBS), $50 \mathrm{mg} / \mathrm{l}$ ascorbate, $10^{-8} \mathrm{M}$ 1,25-dihydroxycholecalciferol, $10^{-6} \mathrm{M}$ prostaglandin $\mathrm{E} 2$ ( $\mathrm{PGE}_{2}$; Alexis, Läufelfingen, Switzerland) and antibiotics. When the medium was changed on day 3, $\mathrm{PGE}_{2}$ was not added further. Osteoblasts were removed on day 5 by treatment with $0.02 \%$ EDTA (3 min) or with $0.02 \%$ collagenase/dispase (Roche Molecular Biochemicals, Basel, Switzerland) dissolved in PBS (20-30 min). The remaining adherent cells were tartrate-resistant acid phosphatase-positive multinuclear cells with less than $10 \%$ mononuclear cells.

The osteoblasts required for the co-culture were prepared as described previously (28). After incubation in $4 \mathrm{mM}$ EDTA-PBS for $30 \mathrm{~min}$, calvaria of 1-3-day-old ddy mice were minced. The bone fragments were incubated in Petri dishes ( $8 \mathrm{~cm}$ diameter) in MEMEarle's containing $50 \mathrm{mg} / \mathrm{l}$ ascorbate, $15 \%$ FBS and $2 \%$ collagen (Cellon SA, Strassen, Luxembourg). After 6 days, the osteoblasts that had grown out from the bone fragments, were harvested by digesting the collagen gel and kept frozen in liquid nitrogen. When required for coculture, the osteoblasts $\left(10^{4} / \mathrm{cm}^{2}\right)$ were grown for 5 days in $\alpha$-MEM-Earle's containing $10 \%$ heat inactivated FBS, $5 \times 10^{-5} \mathrm{M}$ mercaptoethanol, antibiotics and $50 \mathrm{mg} / \mathrm{l}$ ascorbate and collected by trypsin digestion.

Preparation of disaggregated rat osteoclasts Osteoclasts were isolated from tibiae and femurs of 1-2day-old rats as described previously (29). The bones 
were curetted in Medium 199-Hank's. The cells were collected by centrifugation and resuspended in medium containing 30\% FBS. Aliquots of $50 \mu \mathrm{l}$ were pipetted onto $13-\mathrm{mm}$ diameter glass coverslips (four coverslips per rat). The coverslips had been treated overnight with $\mathrm{NaCl}$ solution containing 30\% FBS. After incubation for $1 \mathrm{~h}$ at $37^{\circ} \mathrm{C}$, non-adherent cells were washed off and the osteoclasts adherent to the coverslips treated as described below.

\section{Cell spreading}

The osteoclasts on the coverslips were incubated with or without CSF-1 in Medium 199-Hanks containing $0.1 \%$ bovine serum albumin (BSA)-RIA (Sigma) for $20 \mathrm{~min}$. To test the effect of wortmannin, the cells were pre-incubated for $10 \mathrm{~min}$ in PBS containing the drug or the vehicle (DMSO). After fixation with $4 \%$ paraformaldehyde in PBS, the cells were analyzed under the microscope using phase contrast. Spread osteoclasts were distinguished from non-spread cells according to their form (see Fig. 1). They were counted blinded and expressed as a percentage of the total number of osteoclasts. The area of the cells could not be used for comparison because of the size of individual cells varied too much.

\section{Immunofluorescence}

PI 3-K Osteoclasts on glass cover slips treated \pm CSF-1 were washed with ice-cold PBS containing $1 \mathrm{mM}$ $\mathrm{Na}_{3} \mathrm{VO}_{4}$, fixed with ice-cold 1:1 acetone:methanol $(\mathrm{v} / \mathrm{v})$ and dried at room temperature. Unspecific binding sites were blocked by incubating the cells for $3 \mathrm{~h}$ in PBS containing $0.02 \%$ Tween 20 and $1.5 \%$ donkey serum. They were then incubated overnight at $4{ }^{\circ} \mathrm{C}$ with $2 \mu \mathrm{g} /$ $\mathrm{ml}$ of rabbit antibody against p85 of PI 3-K (Santa Cruz Biotechnology, Dr Glaser AG, Basel, Switzerland) or rabbit IgG (negative control), then for $1 \mathrm{~h}$ at room temperature with biotinylated donkey anti-rabbit IgG antibody (Amersham Pharmacia AG, Zurich, Switzerland), diluted 1:2000, and finally with StreptavidinFluoroLink Cy2 (Amersham Pharmacia), diluted 1:1000. The antibodies and the streptavidin were diluted in PBS containing 0.02\% Tween 20 and 1.5\% donkey serum. After embedding, the preparations were observed with a Nikon fluorescence microscope equipped with a DC $100 \mathrm{~W}$ high pressure mercury lamp and filter HQ470/40 for exiting light (455-485 nm), filter HQ525/50 for the fluorescence light (505-545 nm) and a beam splitter reflecting light $<495 \mathrm{~nm}$.

Phosphotyrosine residues The staining was carried out as described above, except for the following variation. The cells were washed once with ice-cold PBS containing $1 \mathrm{mM} \mathrm{Na} \mathrm{VO}_{4}$, fixed with $4 \%$ formaldehyde dissolved in PHEM (60 mM PIPES, $10 \mathrm{mM}$ HEPES, $10 \mathrm{mM}$ EGTA, $2 \mathrm{mM} \mathrm{MgCl}_{2}$, $\mathrm{pH}$ 6.9), (30) for
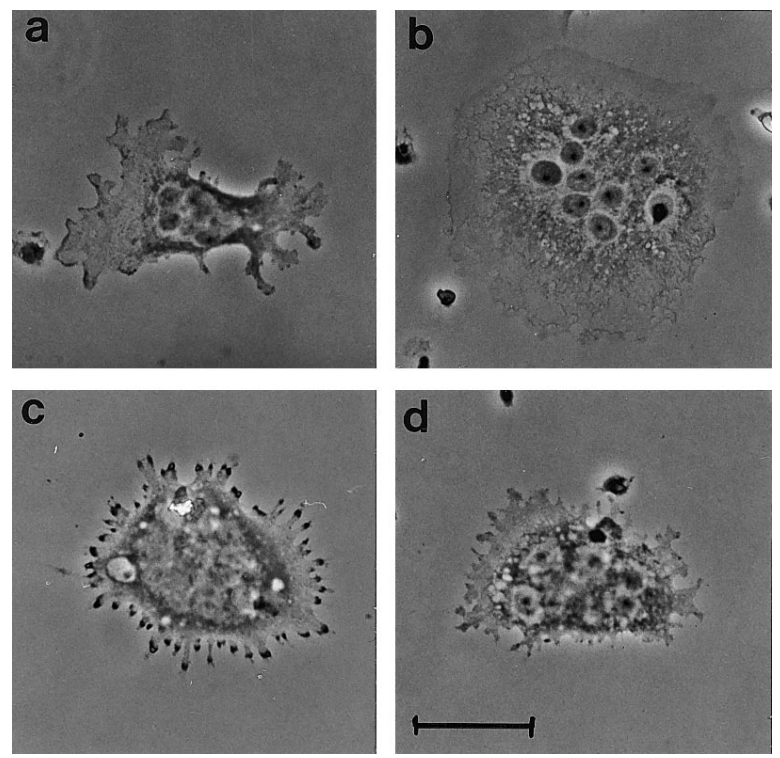

Figure 1 Spreading of disaggregated osteoclasts induced by CSF-1. Osteoclasts were isolated from long bones of 1-2-dayold rats and allowed to adhere to glass coverslips for $1 \mathrm{~h}$. After washing off the non-adhering cells, the osteoclasts were incubated in the absence or presence of $1 \mathrm{nM}$ CSF-1 for $20 \mathrm{~min}$ in Medium 199-Hank's, containing 0.1\% RIA-BSA. Additionally, they were treated with $100 \mathrm{nM}$ wortmannin or the vehicle DMSO. In the absence of CSF-1 (a), the osteoclasts were not spread. In the presence of CSF-1 (b), the osteoclasts, including the granulated area, were spread, and all the nuclei could be identified. The central area was surrounded by an area with low contrast, which was probably thin and contained little cellular material. The granulated area was contracted around the nuclei. In the presence of wortmannin without (c) and with (d) CSF-1, the osteoclasts were not spread in a similar pattern to (a). They had filopodia and small lamellipodia. The nuclei were partially

$15 \mathrm{~min}$ at $37^{\circ} \mathrm{C}$ and washed three times with PBS. For permeabilization, the osteoclasts were treated for $2.5 \mathrm{~min}$ at $37^{\circ} \mathrm{C}$ with $0.5 \%$ Triton X-100 dissolved in PHEM. Unspecific binding was blocked by incubating the cells with PBS containing 1\% BSA and 10\% sheep serum over night at $4{ }^{\circ} \mathrm{C}$. The cells were then incubated for $1 \mathrm{~h}$ at $37^{\circ} \mathrm{C}$ with $20 \mu \mathrm{g} / \mathrm{ml}$ murine monoclonal antibody against phosphotyrosine residues (clone 4G10; Upstate Biotechnology, Lucerna Chem AG, Luzern, Switzerland), then at room temperature with a sheep biotinylated antibody against murine IgG diluted 1:2000 (Amersham Pharmacia), and finally with Streptavidin-FluoroLink Cy2, diluted 1:1000. The antibodies and streptavidin were diluted with PBS containing 1\% RIA-BSA. The fluorescence microscopy was carried out as described above.

\section{Determination of PI 3-K activity in vivo}

For the determination of the PI 3-K activity in the intact osteoclast-like cells, they were grown in dishes of 
$5 \mathrm{~cm}$ diameter, labeled with $\left[{ }^{32} \mathrm{P}^{2} \mathrm{PO}_{4}{ }^{3-}\right.$, and after stimulation with $\pm 3 \mathrm{nM}$ CSF-1, the product of the enzyme reaction was extracted. In detail, the osteoblasts were removed, the osteoclast-like cells washed with phosphate-free Hanks solution and subsequently air-incubated in $\mathrm{PO}_{4}{ }^{3-}$-free MEM containing Hanks salts, $5 \mathrm{mM}$ HEPES, pH 7.3 , and $10 \% \mathrm{FBS}$ at $37{ }^{\circ} \mathrm{C}$ for $1 \mathrm{~h}$. The FBS had been dialyzed against isotonic $\mathrm{NaCl}$ and once against phosphate-free medium. For labeling, the cells were air-incubated in $1.5 \mathrm{ml}$ of the same medium containing $75 \mu \mathrm{Ci}\left[{ }^{32} \mathrm{P}^{2} \mathrm{PO}_{4}{ }^{3-}\right.$ for $1 \mathrm{~h}$. After incubation in PBS with wortmannin or DMSO (DMSO had no effect) for $10 \mathrm{~min}$, the cells were stimulated for various time periods in medium containing \pm CSF- 1 and $10 \%$ heat inactivated FBS. The incubation was terminated by aspirating the medium and adding $1 \mathrm{ml}$ of ice-cold extraction buffer (11 parts $2 \mathrm{mM}$ DTT in $4.8 \mathrm{M} \mathrm{HCl}, 25$ parts $1 \mathrm{mM} \mathrm{CaCl}_{2}, 4.9 \mathrm{mM} \mathrm{KCl}$, $136 \mathrm{mM} \mathrm{NaCl}$ and $10 \mathrm{mM}$ HEPES, pH 7.4, and 64 parts methanol) as described. After addition of $50 \mu \mathrm{g}$ of PIs purified from brain extract (used as carrier and standard), the cellular material of each dish was collected by scraping with a rubber spatula. After sonication for $30 \mathrm{~s}$ and addition of $1.25 \mathrm{ml}$ chloroform, the phospholipids were extracted into the chloroform phase (31). After evaporation under nitrogen they were separated on oxalate-impregnated Silica gel 60 thin layer plates (Merck, Darmstadt, Germany), that were activated at $110{ }^{\circ} \mathrm{C}$ for $40 \mathrm{~min}$ immediately before use. The plates were developed for $4 \mathrm{~h}$ in chloroform:acetone:methanol:acetic acid:water (80:30:26:24:14 v/v). The spots originating from phosphatidylinositol phosphate (PtdInsP), PtdInsP $\mathrm{P}_{2}$ and PtdIns $(3,4,5) \mathrm{P}_{3}$ were identified after exposure to iodide vapor. The radioactivity of the product $\operatorname{Ptd} \operatorname{Ins}(3,4,5) \mathrm{P}_{3}$, which is specific for PI 3-K, was quantified with a PhosphorImager (Storm, Molecular Dynamics). The background on the lane corresponding to each spot was subtracted.

\section{Determination of PI 3-K activity in vitro}

After removal of the osteoblasts, osteoclast-like cells were air-incubated in $\alpha$-MEM-Hanks containing $1 \%$ FBS for $2 \mathrm{~h}$ to up-regulate the CSF-1 receptor. After stimulation with or without CSF-1 for various times, the medium was removed, the cells were washed with ice-cold PBS containing $1 \mathrm{mM} \mathrm{Na} \mathrm{VO}_{4}$ and lysed for $20 \mathrm{~min}$ with $0.4 \mathrm{ml}$ of ice-cold buffer containing $137 \mathrm{mM} \mathrm{NaCl}, 2 \mathrm{mM}$ EDTA, $1 \mathrm{mM} \mathrm{Na} \mathrm{VO}_{4}, 1 \%$ Triton $\mathrm{X}-100,1 \mathrm{mM}$ PMSF, $10 \mu \mathrm{g} / \mathrm{ml}$ leupeptin, $1 \mu \mathrm{g} / \mathrm{ml}$ aprotinin, $10 \mu \mathrm{g} / \mathrm{ml}$ pepstatin and $10 \mathrm{mM}$ Tris-HCl, $\mathrm{pH}$ 7.4. The lysate of two dishes was pooled and centrifuged at $12000 \mathrm{~g}$ for $20 \mathrm{~min}$ at $4{ }^{\circ} \mathrm{C}$. The supernatant $(0.5 \mathrm{ml}$ containing $0.5 \mathrm{mg}$ protein) was cleared for $30 \mathrm{~min}$ with $10 \mu \mathrm{l}$ control serum and $10 \mu \mathrm{l}$ of Gamma Bind G Sepharose Media (Pharmacia Biotech, Dübendorf, Switzerland) and then incubated with $5 \mu \mathrm{g}$ of antibody against phosphotyrosine (Transduction
Laboratories, Mächler AG, Basel, Switzerland) or with IgG (negative control) overnight at $4{ }^{\circ} \mathrm{C}$ under rotation. After incubation with G Sepharose for $2 \mathrm{~h}$ at $4{ }^{\circ} \mathrm{C}$, the beads with the bound immunocomplex were washed three times. For immunoprecipitation of the CSF-1 receptor, an antiserum against the whole protein of this receptor was used (generously donated by E R Stanley, Albert Einstein College of Medicine, Bronx, NY, USA).

The PI 3-K-activity was determined by incubating the immunoprecipitate at $37{ }^{\circ} \mathrm{C}$ for $15 \mathrm{~min}$ in $50 \mu \mathrm{l}$ of the following reaction buffer: $0.2 \mathrm{mM}$ phosphatidylserine, $\quad 0.2 \mathrm{mM} \operatorname{PtdIns}(4,5) \mathrm{P}_{2}, \quad 0.1 \% \quad$ Na-cholate, $50 \mathrm{mM} \mathrm{NaCl}, 10 \mathrm{mM}$ glycerol-3-phosphate, $0.1 \mathrm{mM}$ $\mathrm{Na}_{3} \mathrm{VO}_{4}, 10 \mathrm{mM} \mathrm{NaF}, 5 \mathrm{mM} \mathrm{Na}-\mathrm{PPi}, 20 \mathrm{mM} \mathrm{MgCl}$, $1 \mathrm{mM}$ DTT, $10 \mathrm{mM}\left[\gamma^{-}{ }^{32} \mathrm{P}\right]$ ATP $(2 \mu \mathrm{Ci}$ per tube), and $50 \mathrm{mM}$ Tris- $\mathrm{HCl}, \mathrm{pH}$ 7.5. The phospholipids were dissolved as described (32). The reaction was stopped by the addition of $0.1 \mathrm{ml} 1 \mathrm{~N} \mathrm{HCl}$, and $0.2 \mathrm{ml}$ of a mixture of 1:1 methanol chloroform. The phospholipids were extracted, separated on thin layer plates, and the radioactivity of $\operatorname{PtdIns}(3,4,5) \mathrm{P}_{3}$ determined as described above. The protein was determined by the Bradford method (kit obtained from BIO-RAD, Glattbrugg, Switzerland).

\section{Statistics}

The results are presented as means \pm s.e.M. and analyzed by analysis of variance (Student's NewmanKeuls multiple comparison test).

\section{Results}

\section{Inhibition of cell spreading by wortmannin}

When osteoclasts isolated from long bones of young rats were incubated with CSF-1, they spread and formed circular cells (Fig. 1b). The nuclei were distributed in the granulated area and easy to identify. An area of little contrast, probably very thin, surrounded this granulated area. Wortmannin, an inhibitor of PI 3-K, inhibited spreading (Fig. 1d). In the absence of CSF-1 (Fig. 1a), as well as in the presence of wortmannin (Fig. 1c, d), the cells were not spread, and the largest part of the cell was granulated. The nuclei were partially hidden in the granules. The inhibition of the CSF-1-induced spreading by various concentrations of wortmannin is presented in Fig. 2; half maximal inhibition occurred at a wortmannin concentration of approximately $20 \mathrm{nM}$.

\section{Localization of PI 3-K and phosphotyrosine residues}

The inhibition of the spreading of osteoclasts by wortmannin suggested the involvement of PI $3-\mathrm{K}$ in this process. Immunostaining of the regulatory subunit 


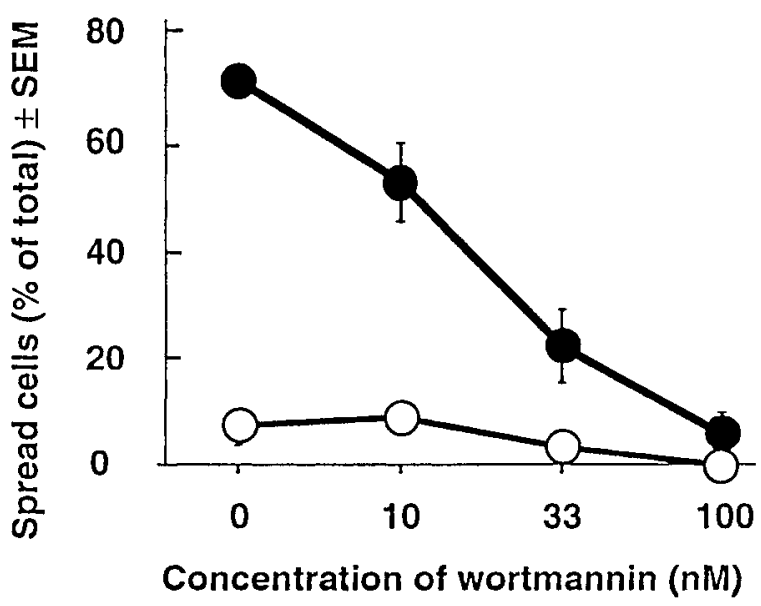

Figure 2 Wortmannin inhibits the CSF-1-induced spreading of disaggregated osteoclasts. Osteoclasts isolated from rat long bones were allowed to adhere to glass coverslips as described in Fig. 1. After pre-incubation with various concentrations of wortmannin or DMSO in PBS, the osteoclasts were treated for 20 min with $1 \mathrm{nM} \mathrm{CSF}-1(\bullet)$ or without CSF-1 (O) as described in Fig. 1. Spread and unspread osteoclasts were counted blinded under the microscope. A total of 170-350 osteoclasts was counted for each treatment. The results present the means \pm S.E.M. of four experiments.

p85 was applied to demonstrate an effect of CSF-1 on this lipid kinase. Figure 3 demonstrates the distribution of PI $3-\mathrm{K}$ in osteoclasts treated with $\pm 3 \mathrm{nM} \mathrm{CSF}-1$. Osteoclasts spread within 2 min of addition of CSF-1 (Fig. 3c), and membrane ruffling appeared (black arrow). A fraction of PI 3-K was translocated to the periphery of the cell, more strongly to sites where membrane ruffling was observed (Fig. 3d and h). The maximal effect was reached $5 \mathrm{~min}$ after addition of CSF-1 and remained for at least for $10 \mathrm{~min}$ (data not shown). In the absence of CSF-1 (Fig. 3b and f) and in the presence of wortmannin (Fig. 3j), PI 3-K remained in the center, in the granulated area of the cell.

Figure 4 demonstrates the distribution of proteins phosphorylated on tyrosine residues in osteoclasts treated with or without CSF-1. In the absence of CSF-1, staining for phosphotyrosine residues appeared inside and at the periphery of the osteoclasts (Fig. 4b, f). Most osteoclasts possessed lamellipodia (Fig. 4b and f), some filopodia (Fig. 4f) staining for phosphotyrosine residues. In a few osteoclasts, rings staining for phosphotyrosine residues were observed inside the cells (Fig. 4b). When CSF-1 was added, the osteoclasts spread and the staining for phosphotyrosine residues at the periphery appeared as a continuous line (Fig. $4 \mathrm{~d}$ and $\mathrm{h}$ ). Wortmannin inhibited spreading and the immunofluorescent signal was distributed similarly to osteoclasts not treated with CSF-1 (Fig. 4j). The similar distribution of PI3-K and tyrosine phosphorylated proteins along the periphery of the spreading osteoclast suggests an interaction between the two.

\section{Activation of PI 3-K activity by CSF-1}

In order to demonstrate the activation of PI 3-K activity by CSF-1, murine osteoclast-like cells were generated in vitro. The enzyme activity was determined by quantitating the product of the enzyme reaction in the cells treated $\pm 3 \mathrm{nM}$ CSF-1. For this purpose, the cells were pre-labeled with $\left[{ }^{32} \mathrm{P}^{3} \mathrm{PO}_{4}{ }^{3-}\right.$. After stimulation with CSF-1, the phospholipids were extracted, separated by thin layer chromatography and the radioactivity of the enzyme product, $\operatorname{PtdIns}(3,4,5) \mathrm{P}_{3}$, was determined. Figure 5 (top) shows the autoradiograph of the thin layer chromatography, and the bottom of the figure shows the quantitation of the autoradiograph. The highest quantity of the product was formed within 2 min of addition of CSF-1. Afterwards PtdIns $(3,4,5) \mathrm{P}_{3}$ decreased slowly and reached control levels after $20 \mathrm{~min}$. Wortmannin (100 nM) inhibited the enzyme reaction to below control levels (about 50\% of control).

The activity of the PI 3-K was also determined in the pellet after immunoprecipitation from the cell lysate with an antibody against phosphotyrosine. As seen in Fig. 6, in osteoclast-like cells treated with CSF-1, the activity of PI 3-K reached a maximum within 2 min and decreased rapidly thereafter. Pre-incubation of the cells with $100 \mathrm{nM}$ wortmannin inhibited the reaction to nearly $0 \%$ of the control. When immunoprecipitated with an antibody against the receptor of CSF-1, the stimulation of PI 3-K activity by CSF-1 was not significantly different to controls (data not shown).

\section{Discussion}

The present results demonstrate the involvement of PI $3-\mathrm{K}$ in the spreading of osteoclasts induced by CSF-1. It has also been demonstrated by others that wortmannin inhibits spreading and chemotaxis of rat osteoclasts (33). Using immunostaining we demonstrated that PI $3-\mathrm{K}$ and proteins phosphorylated on tyrosine residues were localized at the periphery of spreading osteoclasts treated with CSF-1. Furthermore, PI 3-K activated by CSF-1 could be immunoprecipitated with antibody against phosphorylated tyrosine residues. These results suggest an association of PI 3-K with tyrosine phosphorylated proteins at the periphery of spread osteoclasts. Our results are in agreement with those of a recent publication (34).

The effect of CSF-1 has also been investigated in the macrophage cell line BAC1.2F5 (35). A large complex consisting of many proteins phosphorylated and not phosphorylated on tyrosine residues has been isolated from these cells. The results suggest that tyrosine phosphorylation induced by CSF-1 induces the organization of a complex consisting of cytoskeletal and other proteins that mediate the CSF-1-regulated mobility of 

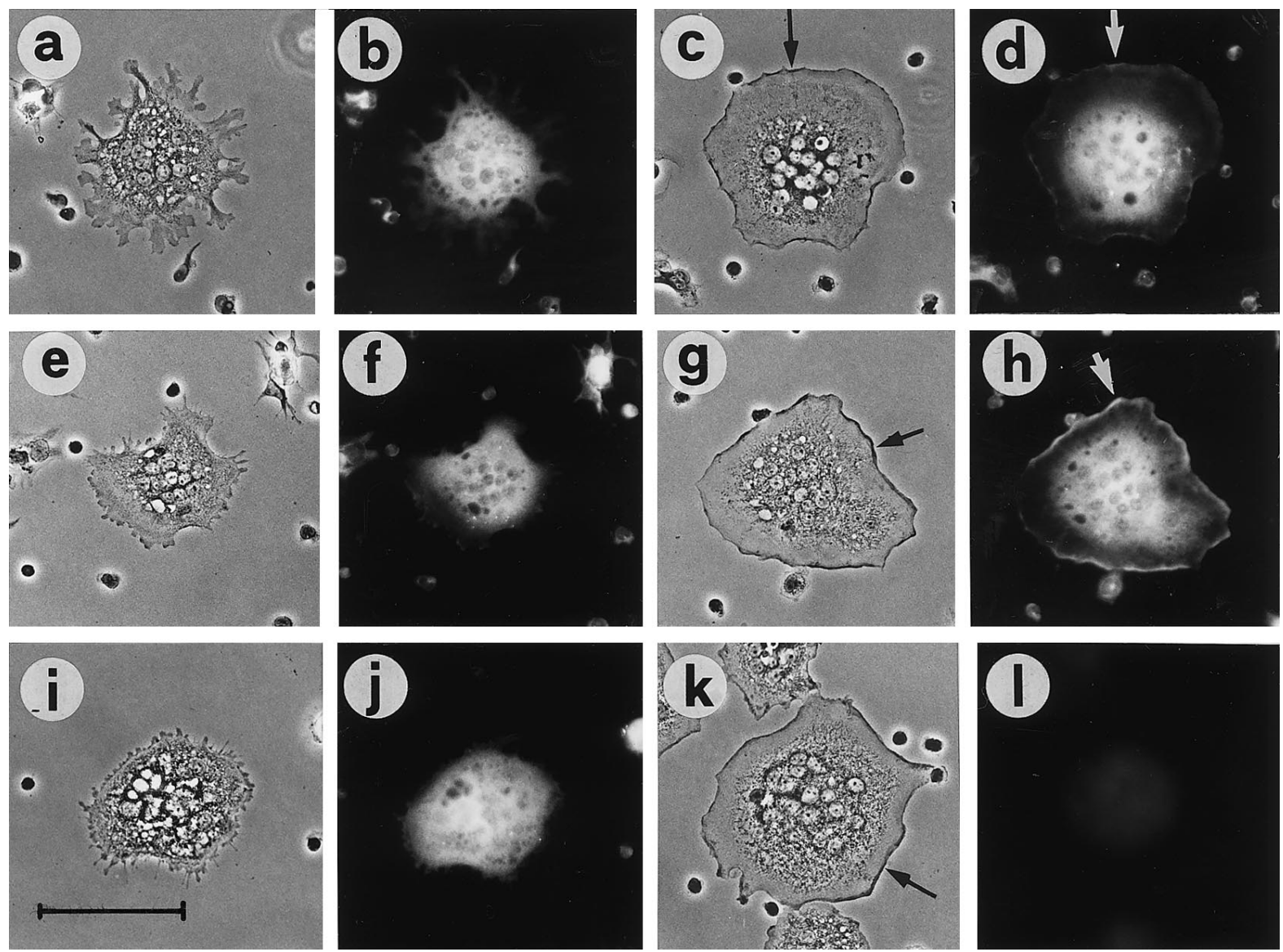

Figure 3 Effect of CSF-1 on the localization of PI 3-K in disaggregated osteoclasts. Osteoclasts isolated from long bones of 1-2-dayold rats were seeded to glass coverslips and after adherence treated $\pm 3 \mathrm{nM} \mathrm{CSF}-1$ for various time periods: 2 min (line 1); 5 min (lines 2 and 3). After fixation, the cells were immunostained with an antibody against the regulatory subunit p85 of PI 3-K and photographed illuminated with light exciting the fluorochrome Cy2 (columns 2 and 4), or with white light using phase contrast (columns 1 and 3 ). In the absence of CSF-1 (a, b, e and f), the osteoclasts remained contracted, and PI 3-K was observed in the center in the granulated area of the cell. On addition of CSF-1 (columns 3 and 4), the osteoclasts spread and membrane ruffling appeared at the periphery of the cell (black arrows in c, g and k). A portion of the PI 3-K appeared at the periphery of the osteoclast, at sites where ruffling was observed (white arrows in $d$ and $h$ ). No immunostaining was observed when the antibody against p85 was replaced by control IgG (k and I). Wortmannin inhibited CSF-1-induced spreading ( $\mathrm{i}$ and $\mathrm{j})$. Scale bar, $100 \mu \mathrm{m}$. The findings described here were observed in three experiments.

macrophages. CSF-1 may have similar effects in osteoclasts.

PI 3-K is activated in that the two SH2 domains of the regulatory subunit p85 interact with tyrosine phosphorylated proteins, which results in the activation of the catalytic subunit p110 $(17,18)$. Thus, it has been demonstrated that PI 3-K interacts with phosphorylated tyrosine residues of the intracellular domain of the activated CSF-1 receptor $(36,37)$; however, we did not observe a significant stimulation of the PI 3-K activity in the pellet immunoprecipitated with an antibody against the CSF-1 receptor (not shown). The reason could be that the activated PI 3-K is not directly associated with the CSF-1-receptor but with proteins phosphorylated on tyrosine that are bound to the receptor. During lysis and immunoprecipitation, the receptor may dissociate from this complex, with PI 3-K remaining bound to proteins phosphorylated on tyrosine. This could explain that PI $3-\mathrm{K}$ activity stimulated by CSF-1 was observed in the pellet immunoprecipitated with antibodies against phosphotyrosine residues but not against the receptor.

An important non-receptor tyrosine kinase in osteoclasts is c-Src. Mice, in which the $c$-src gene has been disrupted, show normal osteoclast development, but bone resorption is impaired (38). c-Src participates in the formation of the ruffled border (39), but it is also required for spreading of osteoclasts induced by CSF-1 $(40,41)$. In avian osteoclasts, c-Src is involved in the activation of PI 3-K induced by osteopontin, a matrix protein that binds to the integrin $\alpha_{v} \beta_{3}$ (42). Grey et al. reported in their recent publication that in osteoclastlike cells stimulated with CSF-1 c-Src associates with its SH3 domain with the proline-rich sequence of the 

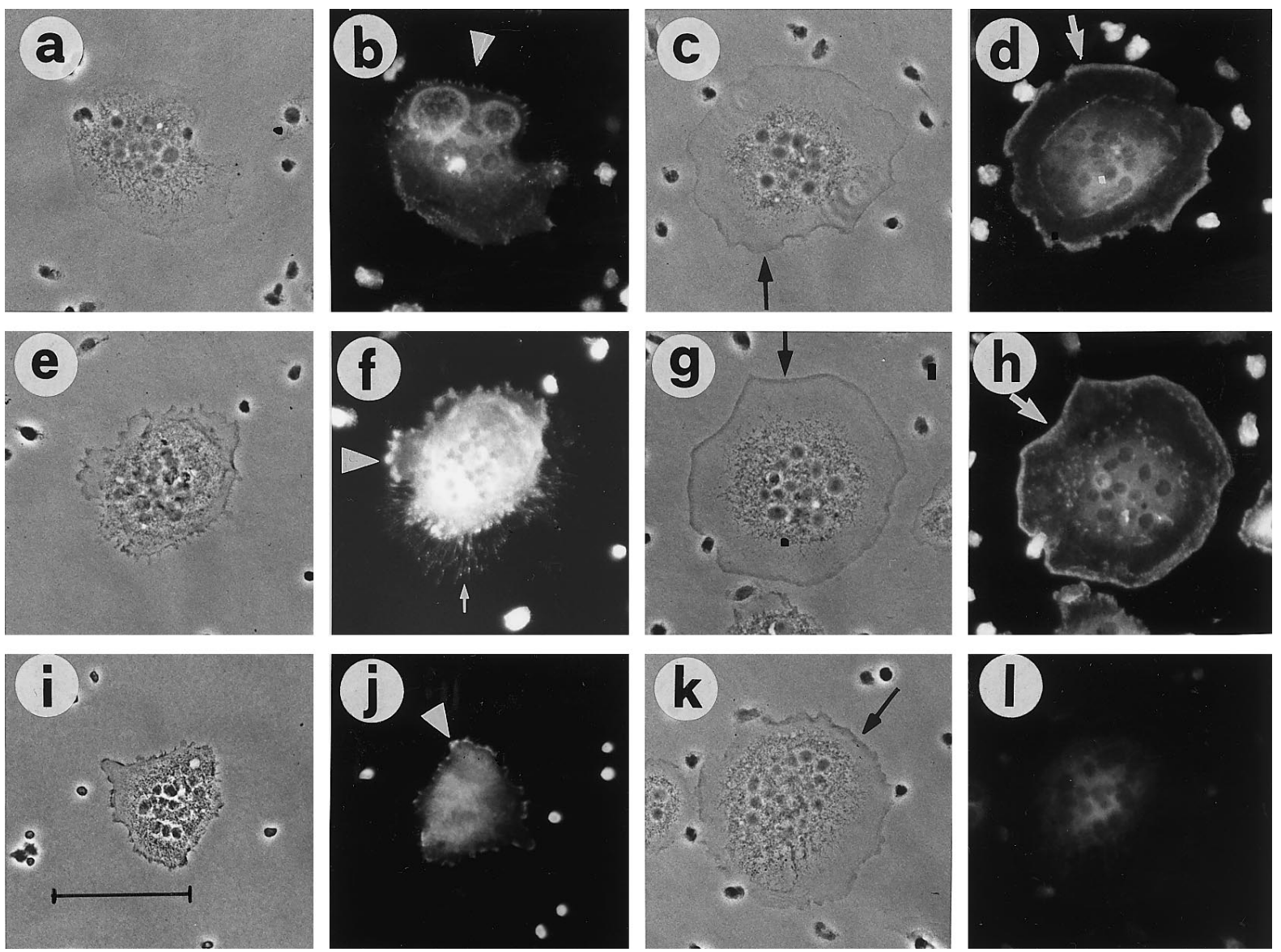

Figure 4 Effect of CSF-1 on the localization of phosphorylated tyrosine residues in disaggregated osteoclasts. Osteoclasts isolated as in Fig. 3 were treated without CSF-1 (columns 1 and 2, except $i$ and j), and with 3 nM CSF-1 (columns 3 and 4 and $i$ and j) for various time periods: 2 min (line 1); 5 min (line 2 and 3). After fixation, the cells were immunostained with an antibody against phosphotyrosine and illuminated with light exciting the fluorochrome Cy2 (columns 2 and 4) or with white light using phase contrast (columns 1 and 3). In the negative control ( $\mathrm{k}$ and I), IgG was added instead of the first antibody. In the absence of CSF-1, the osteoclasts remained contracted (a and e). In the presence of CSF-1, the osteoclasts spread and ruffling appeared at the periphery of the cell (black arrow in $\mathrm{c}, \mathrm{g}$ and $\mathrm{k}$ ), being maximal at $5 \mathrm{~min}$. In the absence of CSF-1, immunostaining for phosphorylated tyrosine residues was observed in the granulated area and at the periphery of the cell. The staining was relatively strong in the center, varied from cell to cell, and was time independent. Two examples are demonstrated in $b$ and $f$. Most osteoclasts possessed lamellipodia (b and f; white arrow head) and some also filopodia (f, small white arrow) staining for phosphotyrosine residues. In the presence of CSF1 , the immunostaining in the center was weaker. At the periphery, it appeared as a continuous line (white arrow in $d$ and $h$ ), similar to that observed for PI 3-K in Fig. 3. When the antibody against phosphotyrosine was replaced with control IgG (k and I), the signal was much weaker. Wortmannin inhibited spreading ( $\mathrm{i}$ and $\mathrm{j}$ ), and the immunostaining appeared in the center and in lamellipodia of the cell. Scale bar, $100 \mu \mathrm{m}$. The findings described here were observed in two experiments.

regulatory subunit p85 of PI $3-\mathrm{K}$ and thus might support the activation of the catalytic subunit p110 (34). Our data do not contradict these results. The antibody against phosphotyrosine residues may immunoprecipitate c-Src associated with PI 3-K.

We observed that the PI 3-K activity of osteoclast-like cells not stimulated with CSF-1 was relatively high, about half of that of cells stimulated with the cytokine. Both activities were inhibited by wortmannin. These results were obtained whether the PI 3-K activity was determined either by quantitating the product of the enzyme reaction in vivo directly in the cultured cells or by measuring the enzyme activity in the pellet immunoprecipitated from cell lysate. The observation could be explained by PI 3-K being not only activated by CSF-1 that induces cell spreading and migration but also by integrins binding to matrix proteins supporting attachment of osteoclasts and finally stimulating the bone resorbing activity. In the culture dish, osteoclastlike cells interact with matrix proteins, which may activate PI 3-K. It has been demonstrated that attachment of osteoclasts to plastic or bone induces a translocation of PI 3-K from the cytosol to the cytoskeleton (25). Furthermore, treatment of chicken osteoclasts with osteopontin activates PI 3-K (42). However, PI 3-K does not seem to be associated with 


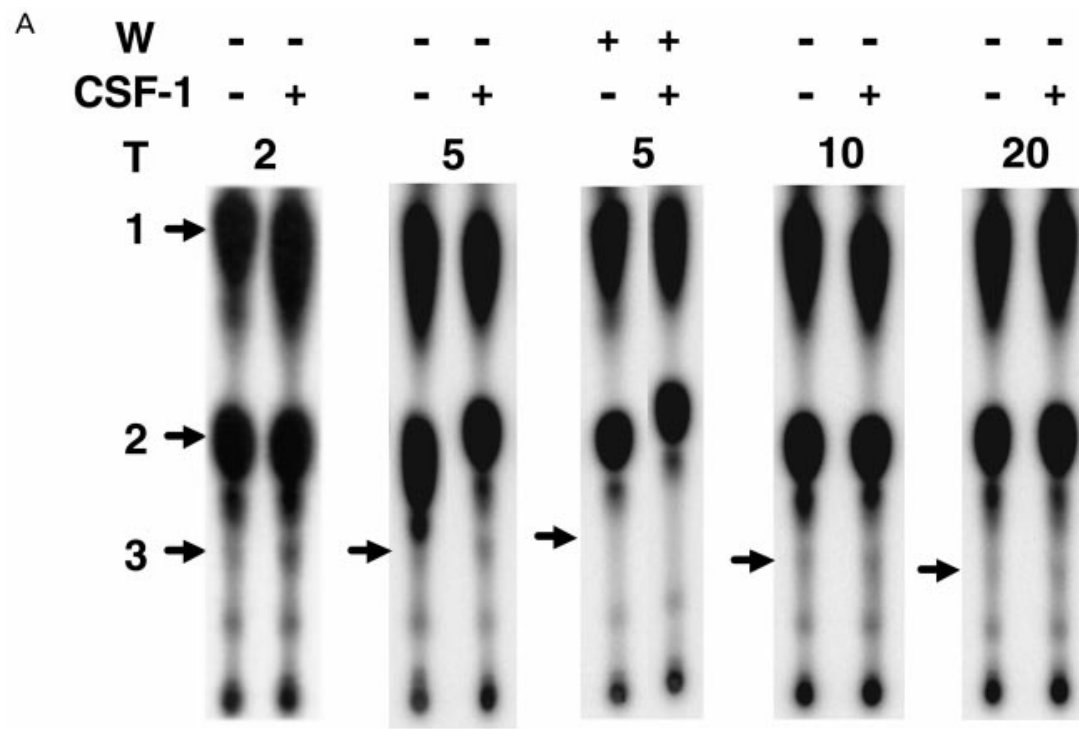

B

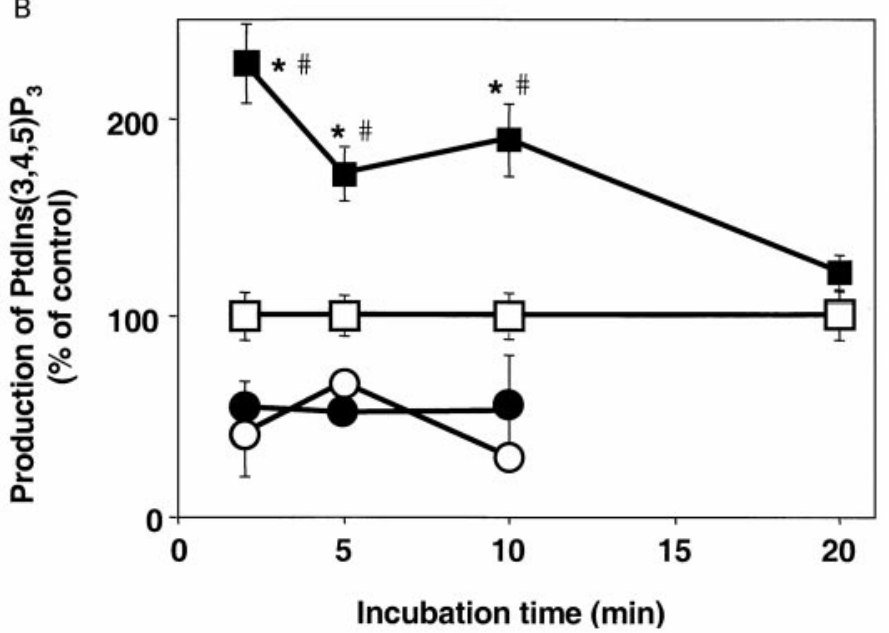

Figure 5 Effect of CSF-1 on PI 3-K activity in osteoclast-like cells in vivo. After removal of the osteoblasts by collagenase/dispase treatment from the osteoclast-like cells grown in co-culture in $5 \mathrm{~cm}$-diameter culture dishes, osteoclastlike cells were labeled with ${ }^{32} \mathrm{P}_{\mathrm{PO}}{ }^{3-}$. The cells were treated \pm 3 nM CSF- 1 for different time periods. The reaction was stopped with an ice-cold mixture of methanol, water and $\mathrm{HCl}$. For the determination of the product of the enzyme reaction, the lipids were extracted and separated by thin layer chromatography. The radioactive spots on the thin layer plate were visualized and determined with a Phosphorlmager. The lower half of the thin layer plate is shown in (A). W, wortmannin; $T$, incubation time in min; 1 , PtdlnsP; 2, Ptdlns $\mathrm{P}_{2} ; 3$, Ptdlns $\left.(3,4,5) \mathrm{P}_{3}\right)$. (B) The radioactivity incorporated into Ptdlns $(3,4,5) \mathrm{P}_{3}$ is presented as a percentage of the control (no CSF-1) as means \pm S.E.M. of 9-20 culture dishes collected from two independent experiments. At $20 \mathrm{~min}$, the experiment was performed only once, assaying three culture dishes. The inhibition by $100 \mathrm{nM}$ wortmannin was tested in 3-5 dishes. (ם), In the presence of CSF-1; $\square$, in the absence of CSF-1; $(\bullet)$ in the presence of CSF-1 + wortmannin; (O) absence of CSF-1 + wortmannin. *Significantly different from control (no CSF-1), $P<0.01$; \# significantly different from CSF-1 + wortmannin, $P<0.01$. p130 ${ }^{\text {Cas }}$ (Crk-associated substrate) and the focal kinase related PYK2 (proline-rich kinase 2), which both localize with cytoskeletal proteins in the actin ring when osteoclasts attach to surfaces coated with $\alpha_{v} \beta_{3}$ integrins (43). The function of PI $3-K$ in the attachment of the osteoclast to the substrate is not yet clear.

PI 3-K is involved in the reorganization of the cytoskeleton, which results in cell spreading and migration of various cell types $(12,15,16)$. The product of the enzyme reaction, $\operatorname{PtdIns}(3,4,5) \mathrm{P}_{3}$, is a phospholipid integrated in the cell membrane. Acting as a second messenger, it binds proteins with a pleckstrin $(\mathrm{PH})$ domain and translocates them to the cell membrane, which results in their activation and signal transduction (14). The signaling proteins inducing migration have not yet been identified fully. Some data suggest that the small GTP-binding proteins Rac and Cdc42, downstream of PI 3-K, activate PAK (p21activated kinase), which finally results in the reorganization of the cytoskeleton (44).
In summary, we suggest that CSF-1 induces the tyrosine phosphorylation of proteins and stimulates PI $3-\mathrm{K}$, which is partially translocated to the periphery of the osteoclast. There, the enzyme may take part in the reorganization of the cytoskeleton required for cell spreading and migration.

\section{Acknowledgements}

We thank members of our department, I. Ryf for correcting the English and W. Hofstetter for helpful discussion. Our thanks also go A. Wetterwald of our department and to S.G. Babb and S.-S. Lim, Department of Anatomy, Indiana University School of Medicine, Indianapolis, USA for advice on immunostaining. We thank Cetus Oncology, Chiron Corporation, Emeryville, CA, USA for donating recombinant human CSF-1, T. Payne, Novartis Pharma AG, Basel, Switzerland for donating wortmannin, Hoffmann-LaRoche, Basel, Switzerland for donating 1,25-dihydroxycholecalciferol, 


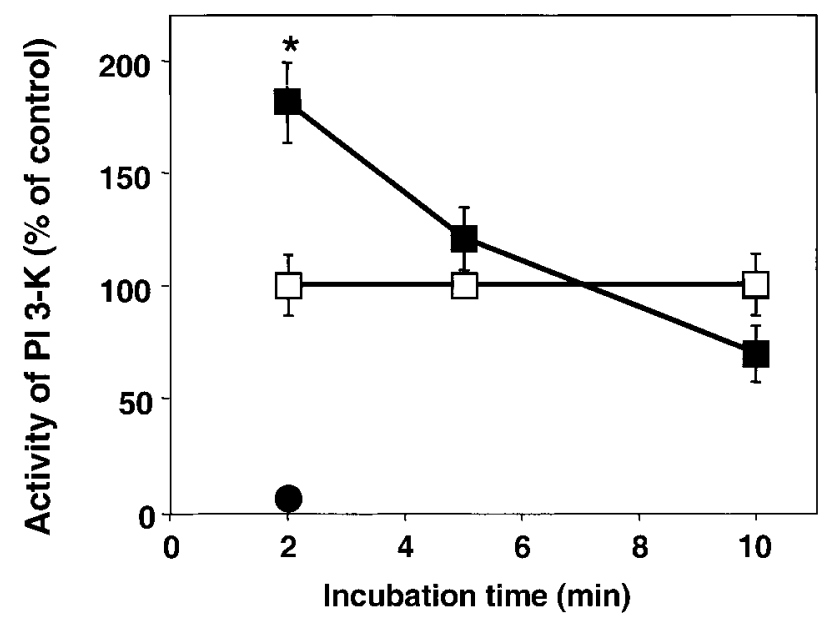

Figure 6 Effect of CSF-1 on PI 3-K-activity in osteoclast-like cells measured in the anti-phosphotyrosine-immunoprecipitate. After removal of the osteoblasts, osteoclast-like cells grown in coculture in $8 \mathrm{~cm}$-diameter culture dishes were preincubated for $2 \mathrm{~h}$ in $\alpha$-MEM, $10 \%$ FBS and then treated with \pm 3 nM CSF-1 for different time periods. After lysis of the cells and immunoprecipitation with antibody against phosphotyrosine, the activity of PI 3-K was measured in the immunoprecipitate. The results are expressed as a percentage of the control (no CSF-1) as means \pm S.E.M. of 5-10 culture dishes of three independent experiments. The inhibition by $100 \mathrm{nM}$ wortmannin was

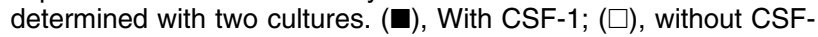

E.R. Stanley, Department of Developmental and Molecular Biology, Albert Einstein College of Medicine, Bronx, NY, USA for donating antisera against the CSF1 receptor and M. Thelen, Kocher Institute, University of Bern, Switzerland for donating an antiserum against p85 and for helpful discussions. This work has been supported by the Swiss National Science Foundation (grants 31-39185.93 and 31-49256.96).

\section{References}

1 Stanley ER. Colony stimulating factor-1 (Macrophage colony stimulating factor). In The Cytokine Handbook, ch 21, pp 387418. Ed A Thomson. London: Academic Press, 1994.

2 Felix R, Hofstetter W, Wetterwald A, Cecchini MG \& Fleisch H. Role of colony-stimulating factor-1 in bone metabolism. Journal of Cellular Biochemistry 199455 340-349.

3 Felix R, Cecchini MG, Hofstetter W, Elford PR, Stutzer A \& Fleisch H. Impairment of macrophage colony-stimulating factor production and lack of resident bone marrow macrophages in the osteopetrotic op/op mouse. Journal of Bone and Mineral Metabolism 19905 781-789.

4 Marks SC Jr. Morphological evidence of reduced bone resorption in osteopetrotic (op) mice. American Journal of Anatomy 1982 $163157-167$.

5 Felix R, Cecchini MG \& Fleisch H. Macrophage colony stimulating factor restores in vivo bone resorption in the op/op osteopetrotic mouse. Endocrinology 1990127 2592-2594.

6 Hofstetter W, Wetterwald A, Cecchini MG, Felix R, Fleisch H \& Mueller C. Detection of transcripts for the receptor for macrophage colony-stimulating factor, c-fms, in murine osteoclasts. PNAS 199289 9637-9641.
7 Hofstetter W, Wetterwald A, Cecchini MG, Mueller C \& Felix R. Detection of transcripts and binding sites for colony-stimulating factor-1 during bone development. Bone 199517 145-151.

8 Weir EC, Horowitz M, Baron R, Centrella M, Kacinski BM \& Insogna KL. Macrophage colony-stimulating factor release and receptor expression in bone cells. Journal of Bone and Mineral Research 19938 1507-1518.

9 Fuller K, Owens JM, Jagger CJ, Wilson A, Moss R \& Chambers TJ. Macrophage colony-stimulating factor stimulates survival and chemotactic behavior in isolated osteoclasts. Journal of Experimental Medicine $1993 \mathbf{1 7 8} 1733-1744$.

10 Amano H, Hofstetter W, Cecchini MG, Fleisch H \& Felix R. Downregulation of colony-stimulating factor-1 (CSF-1) binding by CSF-1 in isolated osteoclasts. Calcified Tissue International 1995 57 367-370.

11 Lees RL \& Heersche JNM. Macrophage colony stimulating factor increases bone resorption in dispersed osteoclast cultures by increasing osteoclast size. Journal of Bone and Mineral Research 199914 937-945.

12 Wennstrom S, Siegbahn A, Yokote K, Arvidsson AK, Heldin CH, Mori S et al. Membrane ruffling and chemotaxis transduced by the PDGF beta-receptor require the binding site for phosphatidylinositol 3' kinase. Oncogene 19949 651-660.

13 Vanhaesebroeck B, Leevers SJ, Panayotou G \& Waterfield MD. Phosphoinositide 3-kinases: a conserved family of signal transducers. Trends in Biochemical Sciences 199722 267-272.

14 Rameh LE \& Cantley LC. The role of phosphoinositide 3-kinase lipid products in cell function. Journal of Biological Chemistry $19992748347-8350$.

15 Duronio V, Scheid MP \& Ettinger S. Downstream signalling events regulated by phosphatidylinositol 3-kinase activity. Cellular Signalling 199810 233-239.

16 Fukui Y, Ihara S \& Nagata S. Downstream of phosphatidylinositol-3 kinase, a multifunctional signaling molecule, and its regulation in cell responses. Journal of Biochemistry (Tokyo) 1998 $1241-7$.

17 Rordorf-Nikolic T, Van Horn DJ, Chen D, White MF \& Backer JM. Regulation of phosphatidylinositol 3'-kinase by tyrosyl phosphoproteins. Full activation requires occupancy of both SH2 domains in the 85-kDa regulatory subunit. Journal of Biological Chemistry $19952703662-3666$.

$18 \mathrm{Yu} \mathrm{J}$, Wjasow C \& Backer JM. Regulation of the p85/p110alpha phosphatidylinositol 3'-kinase. Distinct roles for the n-terminal and c-terminal SH2 domains. Journal of Biological Chemistry 1998 273 30199-30203.

19 Rodriguez-Viciana P, Warne PH, Vanhaesebroeck B, Waterfield MD \& Downward J. Activation of phosphoinositide 3-kinase by interaction with Ras and by point mutation. EMBO Journal $1996152442-2451$.

20 Hall TJ, Jeker H \& Schaueblin M. Wortmannin, a potent inhibitor of phosphatidylinositol 3-kinase, inhibits osteoclastic bone resorption in vitro. Calcified Tissue International $199556336-338$.

21 Nakamura I, Takahashi N, Sasaki T, Tanaka S, Udagawa N, Murakami $\mathrm{H}$ et al. Wortmannin, a specific inhibitor of phosphatidylinositol-3 kinase, blocks osteoclastic bone resorption. FEBS Letters 1995361 79-84.

22 Sato M, Bryant HU, Dodge JA, Davis H, Matter WF \& Vlahos CJ. Effects of wortmannin analogs on bone in vitro and in vivo. Journal of Pharmacology and Experimental Therapeutics 1996277 543-550.

23 Nakamura I, Sasaki T, Tanaka S, Takahashi N, Jimi E, Kurokawa T et al. Phosphatidylinositol-3 kinase is involved in ruffled border formation in osteoclasts. Journal of Cellular Physiology 1997172 230-239.

24 Lakkakorpi PT \& Väänänen HK. Cytoskeletal changes in osteoclasts during the resorption cycle. Microscopy Research and Technique 199633 171-181.

25 Lakkakorpi PT, Wesolowski G, Zimolo Z, Rodan GA \& Rodan SB. Phosphatidylinositol 3-kinase association with the osteoclast cytoskeleton, and its involvement in osteoclast attachment and spreading. Experimental Cell Research 1997237 296-306. 
26 Wymann MP, Bulgarelli-Leva G, Zvelebil MJ, Pirola L, Vanhaesebroeck B, Waterfield MD et al. Wortmannin inactivates phosphoinositide 3-kinase by covalent modification of Lys-802, a residue involved in the phosphate transfer reaction. Molecular and Cellular Biology 199616 1722-1733.

27 Akatsu T, Tamura T, Takahashi N, Udagawa N, Tanaka S, Sasaki $\mathrm{T}$ et al. Preparation and characterization of a mouse osteoclast-like multinucleated cell population. Journal of Bone and Mineral Research 19927 1297-1306.

28 Udagawa N, Chan J, Wada S, Findlay DM, Hamilton JA \& Martin TJ. c-fos antisense DNA inhibits proliferation of osteoclast progenitors in osteoclast development but not macrophage differentiation in vitro. Bone $199618511-516$.

29 Amano H, Yamada S \& Felix R. Colony-stimulating factor-1 stimulates the fusion process in osteoclasts. Journal of Bone and Mineral Research 199813 846-853.

30 Babb SG, Matsudaira P, Sato M, Correia I \& Lim SS. Fimbrin in podosomes of monocyte-derived osteoclasts. Cell Motility and the Cytoskeleton 199737 308-325.

31 Didichenko SA, Tilton B, Hemmings BA, Ballmer-Hofer K \& Thelen M. Constitutive activation of protein kinase $B$ and phosphorylation of $\mathrm{p} 47$ phox by a membrane-targeted phosphoinositide 3-kinase. Current Biology 19966 1271-1278.

32 Stephens LR, Eguinoa A, Erdjument-Bromage H, Lui M, Cooke F, Coadwell J et al. The G $\beta \gamma$ sensitivity of a PI3K is dependent upon a tightly associated adaptor, p101. Cell 199789 105-114.

33 Pilkington MF, Sims SM \& Dixon SJ. Wortmannin inhibits spreading and chemotaxis of rat osteoclasts in in vitro. Journal of Bone and Mineral Research 199813 688-694.

34 Grey A, Chen Y, Paliwal I, Carlberg K \& Insogna K. Evidence for a functional association between phosphatidylinositol 3-kinase and c-src in the spreading response of osteoclasts to colonystimulating factor-1. Endocrinology $2000 \mathbf{1 4 1} 2129-2138$.

35 Yeung YG, Wang Y, Einstein DB, Lee PSW \& Stanley ER. Colonystimulating factor-1 stimulates the formation of multimeric cytosolic complexes of signaling proteins and cytoskeletal components in macrophages. Journal of Biological Chemistry $199827317128-17137$.

36 Shurtleff SA, Downing JR, Rock CO, Hawkins SA, Roussel MF \& Sherr CJ. Structural features of the colony-stimulating factor 1 receptor that affect its association with phosphatidylinositol 3-kinase. EMBO Journal 19909 2415-2421.
37 Reedijk M, Liu X, van der Geer P, Letwin K, Waterfield MD, Hunter $\mathrm{T}$ et al. Tyr721 regulates specific binding of the CSF-1 receptor kinase insert to PI 3'-kinase SH2 domains: a model for SH2-mediated receptor-target interactions. EMBO Journal 1992 11 1365-1372.

38 Soriano P, Montgomery C, Geske R \& Bradley A. Targeted disruption of the c-src proto-oncogene leads to osteopetrosis in mice. Cell 199164 693-702.

39 Tanaka S, Takahashi N, Udagawa N, Sasaki T, Fukui Y, Kurokawa $\mathrm{T}$ et al. Osteoclasts express high levels of p60c-src, preferentially on ruffled border membranes. FEBS Letters 1992 $31385-89$.

40 Insogna KL, Sahni M, Grey AB, Tanaka S, Horne WC, Neff L et al. Colony-stimulating factor-1 induces cytoskeletal reorganization and c-src-dependent tyrosine phosphorylation of selected cellular proteins in rodent osteoclasts. Journal of Clinical Investigation $19971002476-2485$.

41 Teti A, Taranta A, Migliaccio S, Degiorgi A, Santandrea E, Villanova I et al. Colony stimulating factor-1-induced osteoclast spreading depends on substrate and requires the vitronectin receptor and the c-src proto-oncogene. Journal of Bone and Mineral Research 199813 50-58.

42 Chellaiah M, Fitzgerald C, Alvarez U \& Hruska K. c-Src is required for stimulation of gelsolin-associated phosphatidylinositol 3-kinase. Journal of Biological Chemistry 1998273 11908-11916.

43 Lakkakorpi PT, Nakamura I, Nagy RM, Parsons JT, Rodan GA \& Duong LT. Stable association of PYK2 and p(130)Cas in their colocalization in the sealing zone. Journal of Biological Chemistry $19992744900-4907$.

44 Han JW, Luby-Phelps K, Das B, Shu XD, Xia Y, Mosteller RD et al. Role of substrates and products of PI3-kinase in regulating activation of Rac-related guanosine triphosphatases by Vav. Science $1998 \mathbf{2 7 9} 558-560$.

Received 22 June 2000

Accepted 16 November 2000 